\section{Combining ability of sugarcane genotypes based on the selection rates of single cross families}

\author{
Priscilla Neves de Santana ${ }^{1}$, Américo José dos Santos Reis ${ }^{2}$ and \\ Lázaro José Chaves ${ }^{2 *}$
}

\begin{abstract}
This study evaluated the genetic potential of parents used in sugarcane genetic breeding programs based on the performance of previously conducted single crosses. The average selection rate of each family, predicted using Best Linear Unbiased Prediction (BLUP) procedure, was used as a surrogate to the cross performance in the initial evaluation phase. Data analysis was performed using Griffing's method IV adapted for the available set of crosses to detail the general combining ability (GCA) and specific combining ability (SCA) effects. Significant GCA effects were detected, which demonstrated the possibility of selecting parents based on this parameter. SCA had a higher coefficient of determination than GCA. In conclusion, the selection rate is an effective indicator for evaluation of the combining ability of parents in the first selection stage of a sugarcane breeding program.
\end{abstract}

Key words: Saccharum, breeding, general combining ability, specific combining ability.

\section{INTRODUCTION}

Sugarcane genetic breeding has become a decisive factor in sugar alcohol industry development in Brazil, with considerable selection gains over the years and regular release of new cultivars (Barbosa et al. 2012, Ramalho et al. 2012, Daros 2014, laia et al. 2014, Melo et al. 2014, Barbosa et al. 2015, Carneiro et al. 2015).

New sugarcane cultivars are obtained by vegetative propagation of selected genotypes, which are obtained by sexual reproduction of suitable parents. Selection is applied to all breeding stages, from parental choice to the final evaluation phase of the network trials. Individual selection is inefficient during the early stages due to the low heritability coefficients of most traits. Nevertheless, selection based on phenotypic evaluations of individual plants is commonly performed in the early stages of genetic breeding programs (Barbosa et al. 2005, Matsuoka et al. 2005).

Parental selection should fall on genotypes with the characteristics of interest and good cross performances to obtain populations with good performances and containing genes of interest. Parental crosses should be carefully planned, and crosses between related individuals should be avoided to reduce the occurrence of inbreeding depression and the narrowing of the genetic base (Matsuoka et al. 2005).
Crop Breeding and Applied Biotechnology 17: 47-53, 2017 Brazilian Society of Plant Breeding. Printed in Brazil http://dx.doi.org/10.1590/198470332017v17n1a7

.




\section{PN Santana et al.}

The correct choice of parents for crosses depends on the goals and objectives of the genetic breeders, the characteristics of the parents in morphological and agronomic variables, and the progeny performance in previous crosses (Badaloo et al. 1999). The previous performances of the parents may be inferred by calculating the selection rate, which is the ratio between the genotypes selected from each cross and the number of genotypes in that cross. The average selection rate of a parent may be used as an indicator of its general combining ability (Badaloo et al. 1999).

The general combining ability (GCA) is used to estimate the average performance of genotypes in various hybrid combinations and is associated with additive allele effects and additive-by-additive epistatic effects. Conversely, the specific combining ability (SCA) is used to identify specific hybrid combinations that are better or worse than the expected abilities based on the GCA and is associated with gene dominance effects (Halauer et al. 2010).

Genetic variability of the germplasm collection is a basic need for a genetic breeding program. Knowledge of the genetic divergence among genotypes determines the success of hybridization from parental selection. Divergence between genotypes may be indirectly inferred using genealogy data, morphological and agronomic variables, or molecular markers. The SCA of a cross may also be used as an indicator of genetic divergence between parents for a given trait provided that the trait-controlling loci in question show dominance effects (Halauer et al. 2010). This study evaluated the genetic potential of sugarcane parents based on the GCAs estimates using the selection rates of previously generated single-cross families.

\section{MATERIAL AND METHODS}

Populations derived from 3043 single crosses (biparental crosses) involving 541 parents from the sugarcane genetic breeding program of the Inter-University Network for the Development of the Sugar Alcohol Industry (Rede Interuniversitária de Desenvolvimento do Setor Sucroalcooleiro - RIDESA) were used. The single cross progenies were assumed to be full-sib families, although contaminants may occur (Santos et al. 2014). The breeding program crosses were routinely conducted at the Serra do Ouro Flowering and Crossing Station, Murici, Alagoas state, Brazil. The seeds were sent to the federal universities (IFES) that composed the RIDESA (Barbosa et al. 2012). Sowing was performed in each IFES, and seedlings were produced. After a nursery growth phase, the seedlings were used to outline the first selection stage (termed stage T1) and installed in their own areas and experimental areas of associated sugar alcohol industries. In this stage, the best genotypes were selected by visual evaluation and measurements of some basic traits; then, the selected clones advanced to the next stage (termed T2). The average number of replications per family in experimental fields was 2.64 .

The selection rate within each full-sib family evaluated in stage T1 was the basic variable used to evaluate the genetic value of a single cross in the present study. The contribution of each breeding program to the whole set of data used in this study (8045 data) is shown in Table 1. These data refer to crosses series RB 94 to RB 10 (1994 to 2010). The number of crosses series per breeding program varied from five (UFG and UFMT) to 17 (UFV). The variable corresponds to the ratios in percentages between the number of genotypes selected for stage $\mathrm{T} 2$ and the number of genotypes evaluated

Table 1. Number of original data per RIDESA Brazil breeding program and mean effects of selection rates predicted using the BLUP procedure (Intercept $=1.7702$ )

\begin{tabular}{lcc}
\hline Breeding program & Number of data & BLUP - selection rate \\
\hline Universidade Federal de Goiás - UFG & 345 & 1.2817 \\
Universidade Federal de São Carlos - UFSCar & 1628 & 0.8788 \\
Universidade Federal de Alagoas - UFAL & 2497 & 0.2524 \\
Universidade Federal do Paraná - UFPR & 1033 & -0.1072 \\
Universidade Federal do Mato Grosso - UFMT & 190 & -0.1675 \\
Universidade Federal de Pernambuco - UFRPE & 124 & -0.3334 \\
Universidade Federal de Viçosa - UFV & 1878 & -0.8276 \\
Universidade Federal Rural do Rio de Janeiro - UFRRJ & 350 & -0.9772 \\
Total & 8045 & - \\
\hline
\end{tabular}


in stage T1. Only parents that participated in two or more crosses were analyzed to allow GCA estimation.

The selection rates of each cross were predicted using the Best Linear Unbiased Predictor (BLUP) method according to the model: $Y_{i j k}=\mu+\tau_{i}+\alpha_{j}+\rho_{k}+\varepsilon_{i j k} ;$ where, $Y_{i j k}$ : selection rate (\%) from the cross $k$, in the year $j$, in IFES $i ; \mu$ : effect of the mean (intercept), fixed, with $E(\mu)=\mu$ and $E\left(\mu^{2}\right)=\mu^{2} ; \tau_{i}$ : effect of IFES (breeding program), random, with $E\left(\tau_{j}\right)=0$ and $E\left(\tau_{j}^{2}\right)=\sigma_{\tau^{\prime}}^{2} ; \alpha_{j}$ : effect of year $j$, random, with $E\left(\alpha_{j}\right)=0$ and $E\left(\alpha_{j}^{2}\right)=\sigma_{\alpha^{\prime}}^{2} \rho_{k}$ : effect of cross $k$, random, with $E\left(\rho_{k}\right)=0$ and $E\left(\rho_{k}^{2}\right)$ $=\sigma_{\rho}^{2} ; \varepsilon_{i j k}$ : error (deviation) associated with the observation $Y_{i j k^{\prime}}$, random, with $E\left(\varepsilon_{i j k}\right)=0$ and $E\left(\varepsilon_{i j k}^{2}\right)=\sigma_{\varepsilon}^{2}$. This procedure was adopted to minimize differences in the selection criteria of each program and other unmeasured effects between experiments. The predicted value of a specific cross $\left(\rho_{k}, k=1,2, \ldots, 3043\right)$ representing the adjusted average performance of its progeny in stage T1 was used to outline a partial diallel table. The use of the Restricted Maximum Likelihood (REML) mixed models method in sugarcane genetic breeding has been used for several authors (Barbosa et al. 2005, Barbosa et al. 2012, Silva et al. 2015).

Model I: Method IV proposed by Griffing (1956) was used for the combining ability analysis as follows: $Y_{i j}=\mu+g_{i}+$ $g_{j}+s_{i j}$, wherein $Y_{i j}$ is the BLUP value regarding the cross between parents $i$ and $j, \mu$ is the overall mean, $g_{i}$ and $g_{j}$ are the general combining ability (GCA) effects of the $i^{t h}$ and $j^{t h}$ parents, respectively $(i<j=2,3 \ldots, 541)$, and $s_{i j} s_{i j}$ is the specific combining ability (SCA) effect of the cross between the $i$ - and $j$-order parents.

The estimates of the effects and their respective sums of squares were obtained using the least squares method. The model is described using matrix notation as follows: $Y=X B+\varepsilon$, wherein $Y$ is the vector of observed means, $X$ is the incidence matrix, $B$ is the vector of parameters and $\varepsilon$ is the vector of deviations from the model. Some restrictions, like the sum of estimates equal to zero, were added to obtain unique solutions for the vector $b$ estimate.

The matrix $X$ was constructed using the reduced model $Y_{i j}=\mu+g_{i}+g_{j}$. The parameter estimates were obtained by $\hat{B}$ $=\left(X^{\prime} X\right)^{-1}\left(X^{\prime} Y\right)$. The sum of squares of the model was obtained by $S S_{\text {Model }}=\hat{B}\left(X^{\prime} Y\right)$. SCA estimates were obtained by the differences between the observed value of each cross and predicted values by model based on GCA $\left(\hat{g}_{i}\right.$ and $\left.\hat{g}_{j}\right)$ (i.e., $S=$ $Y-\hat{X} B$, wherein $S$ is the vector of $S_{i j}$ estimates). The sums of squares of the diallel analysis were obtained by $S S_{S C A}=Y^{\prime} Y-$

$S S_{\text {Model }}$ and $S S_{G C A}=S S_{\text {Model }}-C ; C$ is the sum of squares regarding the constant of the model. The analysis was performed using a specific script in the $R$ environment ( $R$ Core Team 2014).

\section{RESULTS AND DISCUSSION}

\section{Selection rate}

The selection rate varied considerably between RIDESA member institutions depending on the purpose of each program, the experimental area, the material availability, the subjective evaluation of the breeder, and the year and site in which the materials were evaluated in stage T1. The average selection rate calculated from 8045 data points resulting from 3043 different crosses was $1.84 \%$ of genotypes selected per family, with a range from $0 \%$ to $90 \%$ and a $142.04 \%$ coefficient of variation, which shows a wide variation of selection rates among crosses and among experiments. Most values ranged from $0 \%$ to $5 \%$, thereby generating a frequency distribution skewed to near-zero values; values higher than $10 \%$ were rare (Figure 1a). Applying the BLUP procedure to predict the genetic values of crosses proved efficient and generated a frequency distribution similar to the standard normal curve, with the higher frequency classes close to zero (Figure 1b).

The selection rate used in the present study to evaluate the genetic potential of the parents was a composite variable derived from different primary variables used in the T1 selection stage of the RIDESA sugarcane genetic breeding program. Conceptually, the selection rate may be considered a selection index because it encompasses several variables, including vigor, health, height, and stalk diameter, depending on the criteria adopted in each IFES. High selection rates are generated in crosses (families) with higher means and phenotypic variability when considering a single selection criterion and the same sample size. Populations with low means and variances generate low or null selection rates, whereas average rates occur in populations with a low mean and high variance, high mean and low variance or with both parameters with intermediate values.

The average selection rate per cross predicted using the BLUP method had values ranging from -0.692 to 4.734 , with 
(a)

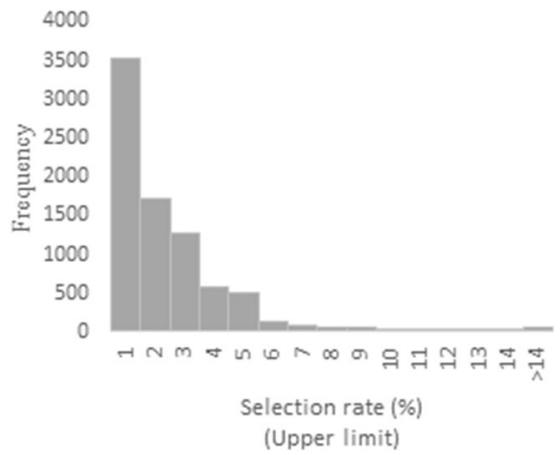

(b)

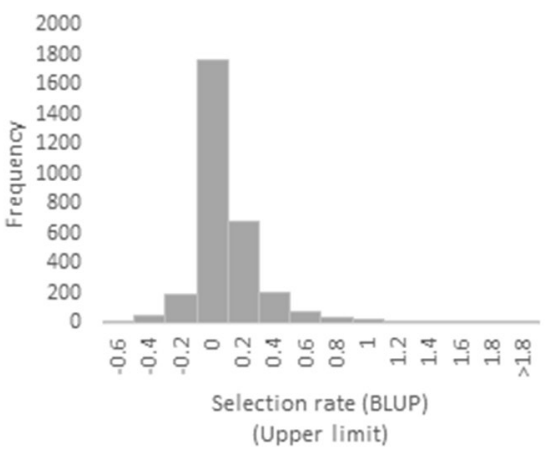

Figure 1. Histograms of the frequencies of selection rate values: a) original data (8045 values); b) mean values of 3043 crosses predicted using the BLUP procedure.

a 1.7702 intercept (Figure 1b). The effects of institutions ranged from -0.977 (Federal Rural University of Rio de Janeiro - UFRRJ) to 1.281 (Federal University of Goiás - UFG). These values showed the different selection intensities in T1 stage between institutions (Table 1).

\section{Analysis of variance}

The results from the analysis of variance performed according to the model by Griffing (1956) adapted for the available set of crosses are outlined in Table 2. A mean squared error on the same scale as the other mean squares was not available because the BLUP values used in the analysis were obtained at the level of means of crosses. Thus, the significance of the general combining ability (GCA) was tested using the $\mathrm{F}$ test with the mean square of the specific combining ability (SCA) as a denominator, which is a conservative test that is equivalent to considering the parental effects as random. The $\mathrm{F}$ test was significant at a $0.1 \%$ probability level for the GCA effect. The significance of the SCA was not tested using the F test for the aforementioned reason.

Table 2 also outlines the coefficients of determination for GCA (0.231) and SCA (0.769). These values indicate that $76.9 \%$ of the total data variation results from SCA and $23.1 \%$ from GCA. Although the significance of the mean squared SCA was not tested, the $R^{2}$ value demonstrated the importance of this effect for the determination of data variation compared with the GCA. These results demonstrate the possibility of parental selection for future crosses based on the GCA and the existence of specific complementation shown in particular crosses.

The results from the GCA and SCA analysis using diallelic models are usually interpreted regarding genetic effects; the GCA is predominantly associated with the additive effects and the SCA with the non-additive effects of the genes (Silva et al. 2002, Camacho et al. 2015). This interpretation seemed inappropriate in the present case because the variable was a composite variable and a large number of diverse primary variables were analyzed in the selection. The SCA shown using this model may at least partially result from the interaction between genotypes and the test environments.

\section{General combining ability}

The present study focused more on the GCA effects for both the reliability and its statistical significance; the SCA effects were estimated for a limited number of crosses compared to the total crosses possible if a full diallel was available. 
Estimates of the general combining ability effects for the 541 parents ranged from 0.454 to -0.353 . These values showed that the best parent added 0.45 percentage points to the selection rate (predicted using the BLUP procedure) of crosses in which the best parent participated. Considering that the prediction intercept was 1.770 , the best parent was $25.6 \%$ higher than the average of all parents. On the opposite end, the parent that contributed least to the crosses was $19.9 \%$ lower than the parental average. The GCA estimation method reported herein consists in modeling the concept introduced by Badaloo et al. (1999) in which the average selection rate of a parent is indicative of its GCA.

The 50 best genotypes regarding the GCA are outlined in Table 3. These parents are potentially the best based on the contribution of the highest positive values of the general combining ability effects. For these, the number of evaluated crosses per parent varied from two to 110 (Table 3). Among the 50 best parents, 29 participated of four or more crosses, allowing an acceptable accuracy for the estimates of GCA. Simulated study on the efficiency of partial circulant diallels showed good coincidence of the estimates of GCA with complete diallels, even with small number of crossings per parent (Veiga et al. 2000). A total of 1225 single crosses would be possible with these parents. The choice of crosses to be performed could consider other criteria, including genetic diversity and complementarity between parents, and specific characteristics according to the demands of each program. Some of the parents with the best GCAs outlined in Table 3 are commercial varieties cropped in Brazil, including RB855453, RB987935, SP832847, SP801816 and SP803280 (Chapola et al. 2013, Daros 2014). Only RB855453 was among the eight most planted varieties in 2011 (Barbosa et al. 2012).

Table 3. Estimates of general combining ability effects () and number of crosses (NC) for the 50 best sugarcane parents

\begin{tabular}{|c|c|c|c|c|c|c|c|}
\hline Rank & Genotype & NC & GCA & Rank & Genotype & NC & GCA \\
\hline 1 & RB7893 & 2 & 0.4538 & 26 & RB945957 & 3 & 0.1761 \\
\hline 2 & RB945956 & 9 & 0.4227 & 27 & RB855589 & 22 & 0.1742 \\
\hline 4 & RB951558 & 3 & 0.4179 & 29 & RB00509 & 11 & 0.1725 \\
\hline 5 & B70710 & 4 & 0.3712 & 30 & RB991555 & 8 & 0.1723 \\
\hline 7 & RB99710 & 2 & 0.3299 & 32 & SP801816 & 90 & 0.1703 \\
\hline 8 & JA6420 & 2 & 0.3118 & 33 & RB957712 & 17 & 0.1669 \\
\hline 9 & RB865513 & 8 & 0.2922 & 34 & RB00512 & 6 & 0.1657 \\
\hline 10 & CP82550 & 4 & 0.2889 & 35 & RB951521 & 2 & 0.1640 \\
\hline 14 & RB97327 & 2 & 0.2529 & 39 & RB95549 & 5 & 0.1518 \\
\hline 15 & CB3822 & 8 & 0.2245 & 40 & RB931546 & 2 & 0.1483 \\
\hline 16 & RB987935 & 9 & 0.2090 & 41 & SP831483 & 3 & 0.1465 \\
\hline 17 & RB735200 & 11 & 0.2044 & 42 & RB997810 & 2 & 0.1431 \\
\hline 18 & RB758516 & 4 & 0.2036 & 43 & RB855453 & 26 & 0.1415 \\
\hline 19 & HJ5741 & 2 & 0.2008 & 44 & CB654 & 2 & 0.1328 \\
\hline 20 & SP853877 & 16 & 0.1918 & 45 & SP811663 & 9 & 0.1325 \\
\hline 21 & RB9358 & 2 & 0.1880 & 46 & H566724 & 4 & 0.1320 \\
\hline
\end{tabular}




\section{PN Santana et al.}

Heterogeneity for GCA is of great relevance because the existence of genetic diversity among genotypes is important to generate genetic variability and obtain genetic gains on the variables selected in the T1 stage of the genetic breeding programs.

\section{Specific combining ability}

The estimates of SCA effects relative to the 3043 hybrid combinations ranged from 4.080 to -0.948 according to the model by Griffing (1956). This estimate had a noticeably higher value (4.080) and thus might be considered an outlier regarding the distribution of values concentrated below 2.0. This cross between parents RB945956 and IAC873396 had only 10 genotypes in the first selection stage in one of the environments; nine genotypes were selected for the following stages generating a selection rate of $90 \%$.

As shown by the coefficient of determination $\left(R^{2}\right)$, the SCA was high, with approximately $77 \%$ of the total variation of the BLUPs of selection (Table 2). Therefore, the extreme SCA values were noticeably higher in absolute values than the GCA values. Thus, selection may also be performed based on the SCA estimates.

A total of 146,070 hybrid combinations could be obtained using the 541 parents available. Only 3043 of these combinations were evaluated and used to perform the SCA predictions, which was a small percentage of the total that could be studied. Nevertheless, the number of crosses performed was high and might be considered a representative sample of the possible crosses. The genetic potential of the non-evaluated crosses could be estimated based on a reduced model that only analyzed the GCA of those parents (Reis et al. 2005).

SCA estimates enabled the identification of the most promising hybrid combinations to obtain families for genetic breeding programs. From a practical standpoint, crosses with high potential that were previously underexploited could be exploited using a larger sample. The following were the best hybrid combinations in terms of SCA: RB945956 with IAC87-3396, SP80-1816 with RB855063, RB72454 with RB721012, RB855063 with RB855127, RB008304 with RB92579, and RB955970 with SP91-1049.

Table 3 shows that some of the best parents in GCA are involved in the crosses with the highest SCAs. Parent SP832847 is noteworthy; this parent had a high GCA and participated in seven of the 45 best crosses. Similarly, parent SP775181 ranked $28^{\text {th }}$ regarding the GCA values (Table 3 ) and participated in five crosses with good specific combining ability. Parent SP80-1816, which participated in six crosses with the best SCA, was also noteworthy.

The effect of SCA is associated with deviations from the mean cross compared to the expected outcome based on the GCA, which results from genetic complementation between parents. Thus, the selection of hybrid combinations with more favorable SCA estimates involving at least one parent with favorable GCA effects is recommended (Bressiani et al. 2002).

The genetic variability that exists between the parents noticeably indicates the possibility of successful selection. However, the selection rate variable, which is composed of other variables, hinders the comparison of the results obtained in this study with other studies because they are based on primary variables (i.e., each trait is individually evaluated), such as soluble solids (Brix), polarizable sugars (POL), tons of sugarcane per hectare $(\mathrm{TCH}$ ) and stalk number (Bressiani et al. 2002, Silva et al. 2002, Bastos et al. 2003).

GCA has been mostly prioritized in parental selection complemented by SCA, which is also significant for various traits. Thus, it is best to use analyses based on primary variables when selecting individual traits to enable the identification of genotypes or hybrid combinations for the trait of interest. Conversely, the present study demonstrates the viability of using a composite variable to evaluate both parents and hybrid combinations. This procedure allows the use of data from previous cross performances of the parents in a single analysis, thereby enabling the planning of future crosses without conducting diallel crosses, which are labor-intensive and limit the number of parents that may be evaluated. In this case, GCA-based selection should be prioritized as an indicator of the genetic value of the parents. SCA-based selection can be performed within the evaluated set of crosses, and those with the greatest potential may be repeated using a more appropriate sample.

\section{ACKNOWLEDGEMENTS}


The authors thank the RIDESA, Brazil for financial support and the coordinators of sugarcane breeding programs Antônio Marcos laia (UFMT), Djalma Euzébio Simões Neto (UFRPE), Edelclaiton Daros (UFPR), Geraldo Veríssimo de Souza Barbosa (UFAL), Hermann Paulo Roffmann (UFSCar), Jair Felipe Garcia Pereira Ramalho (UFRRJ) and Márcio Henrique Pereira Barbosa (UFV), for sharing the data used in this study. The authors also thank the National Council for Scientific and Technological Development (CNPq, Brazil), for research grant to LJ Chaves and scholarship grant to PN Santana.

\section{REFERENCES}

Badaloo GH, Domaingue R and Ramdoyal KA (1999) Critical review of parental choice and cross prediction techniques in the MSIRI sugar cane breeding program. In Lalouette JA, Bachraz DY and Sukurdeep $\mathrm{N}$ (eds) Proceedings third annual meeting of agricultural scientists. Food and Agricultural Research Council Reduit, Mauritius, p. 47-54.

Barbosa MHP, Resende MDV, Bressiani JA, Silveira LCI and Peternelli LA (2005) Selection of sugarcane families and parents by Reml/Blup. Crop Breeding and Applied Biotechnology 5: 443-450.

Barbosa MHP, Resende MDV, Dias LAS, Barbosa GVS, Oliveira RA, Peternelli LA and Daros E (2012) Genetic improvement of sugar cane for bioenergy: The Brazilian experience in network research with RIDESA. Crop Breeding and Applied Biotechnology S2: 87-98.

Barbosa GVS, Oliveira RA, Cruz MM, Santos JM, Silva PP, Viveiros AJA, Sousa AJR, Ribeiro CAG, Soares L, Teodoro I, Sampaio Filho F, Diniz CA and Torres VLD (2015) RB99395: Sugarcane cultivar with high sucrose content. Crop Breeding and Applied Biotechnology 15: 187-190.

Bastos IT, Barbosa MHP, Cruz CD, Burnquist W, Bressiani JA and Silva F L (2003) Análise dialélica em clones de cana-de-açúcar. Bragantia 62: 199-206.

Bressiani JA, Burnquist WL, Fuzatto SR, Bonato ALV and Geraldi IO (2002) Combining ability in eight selected clones of sugarcane (Saccharum sp). Crop Breeding and Applied Biotechnology 2: 411-416.

Camacho LRS, Scapim CA, Senhorinho HJC and Conrado TV (2015) Diallel analysis of popcorn lines and hybrids for baby corn production. Crop Breeding and Applied Biotechnology 15: 33-39.

Carneiro MS, Chapola RG, Fernandes Junior AR, Cursi DE, Barreto FZ, Balsalobre TWA and Hoffmann HP (2015) RB975952 - Early maturing sugarcane cultivar. Crop Breeding and Applied Biotechnology 15: 193-196.

Chapola RG, Cruz JÁ, Nunes IK and Fernandes JAR (2013) Censo varietal 2012. Universidade Federal de São Carlos, Centro de Ciências Agrárias, São Carlos, 55p.

Daros E (ed) (2014) Clones RB de cana-de-açucar. Graciosa, Curitiba, 112p.

Griffing B (1956) Concept of general and specific combining ability in relation to diallel crossing systems. Australian Journal of Biological
Science 9: 463-493.

Halauer AR, Carena MJ and Miranda Filho JB (2010) Quantitative genetics in maize breeding. Springer, New York, 663p.

Iaia AM, Oliveira RA, Melo LJOT, Daros E, Simões Neto DE, Bastos GQ, Oliveira FJ, Chaves A and Melo TTAT (2014) RB002504 - New early-maturing sugarcane cultivar. Crop Breeding and Applied Biotechnology 14: 45-47.

Matsuoka S, Garcia AAF and Arizono H (2005) Melhoramento da canade-açúcar. In Borém A (ed) Melhoramento de espécies cultivadas. $2^{\text {nd }}$ edn, Editora UFV, Viçosa, p. 205-251.

Melo LJOT, Daros E, Simões Neto DE, Chaves A, Silva LJ, Silva AEP and Melo TTAT (2014) RB962962, a sugarcane cultivar for late harvest. Crop Breeding and Applied Biotechnology 14: 132-135.

R Core Team (2014) R: A language and environment for statistical computing. R Foundation for Statistical Computing, Vienna. Available at <http://www.R-project.org/>. Accessed in 15 Jun, 2013

Ramalho MAP, Dias LAS and Carvalho BL (2012) Contributions of plant breeding in Brazil - progress and perspectives. Crop Breeding and Applied Biotechnology 2: 107-112.

Reis AJS, Chaves LJ, Duarte JB and Brasil EM (2005) Prediction of hybrid means from a partial circulant diallel table using the ordinary least square and the mixed model methods. Genetics and Molecular Biology 28: 314-320.

Santos JM, Barbosa GVS, Ramalho Neto CE and Almeida C (2014) Efficiency of biparental crossing in sugarcane analyzed by SSR markers. Crop Breeding and Applied Biotechnology 14:102-107.

Silva MA, Landell MGA, Gonçalves PS, Bressiani JA and Campana MP (2002) Estimates of general and specific combining ability for yield components in a partial sugarcane diallel cross. Crop Breeding and Applied Biotechnology S2: 111-120.

Silva FL, Barbosa MHP, Resende MDV, Peternelli LA and Pedrozo CA (2015) Efficiency of selection within sugarcane families via simulated individual BLUP. Crop Breeding and Applied Biotechnology 15: 1-9.

Veiga RD, Ferreira DF and Ramalho MAP (2000) Eficiência dos dialelos circulantes na escolha de genitores. Pesquisa Agropecuária Brasileira 35: 1395-1406. 